\title{
Painless Inter Epididymal Testicular Torsion of the Spermatic Cord
}

\author{
Salomon V. Romano, Haime S. Hernan, Norberto Fredotovich
}

Section of Urology, Hospital Durand, Buenos Aires, Argentina

\begin{abstract}
Inter epididymal testicular torsion of the spermatic cord is extremely rare and usually diagnosed at surgery. We present an unusual case of spermatic cord torsion in a 14-year-old male patient. It is important to highlight that the torsion occurred only on the distal half of the epididymis leaving the head untwisted and edematous. In addition, the fact that this condition was painless made this case extremely rare and motivated our presentation.
\end{abstract}

\section{INTRODUCTION}

Testicular torsion is considered a surgical emergency. The testis present irreversible damage if the torsion is not resolved within the first 6 hours. Torsion usually occurs in young pre-puberty males, between 12 and 18 years old, (1) even though it can be seen in other ages. The prevalence is estimated to be 1 in 4000 patients under 25 years old.

The inter epididymal torsion of the spermatic cord is one of the most infrequent situations. In our patient it occurred due to the abnormal insertion between the epididymis and the testicle. This kind of torsion is clinically undistinguishable from the typical spermatic cord torsion and the diagnosis can only be made during surgical exploration.

It is well known that spermatic cord torsion is associated with intense pain. In this particular case, it was painless.

\section{CASE REPORT}

A fourteen-year-old male patient was first seen at the urology section due to a painless growth of his left scrotum, beginning one month before his visit. No history of trauma or masturbation habit was refereed, but a similar episode took place 2 years before, with complete remission after medical treatment.

Previous evaluation in another center with ultrasonography (US) and tumor markers assumed its etiology as inflammatory and as a consequence treated the condition with ice, antibiotics and oral analgesics.

At physical examination, an increased volume and high consistence on left testicle was found, but the patient said the size was half of what it was initially, without spontaneous or induced pain.

The US showed a homogeneous round left testicle, without tumor, with a para-testicular solid 
$16 \times 21 \mathrm{~mm}$ hypoechoic mass with small hydrocele (Figure-1).

Blood flow was normal according to a color Doppler ultrasonography. Contralateral (right) testis and epididymis were normal.

The left testicle was explored using the inguinal approach, showing a partial intravaginal 360degrees inter epididymal testicular torsion of spermatic cord. The torsion site was in the epididymal corpus, leaving the head in place (Figure-2), corresponding to the hypoechoic mass described previously. The necrotic aspect of the testicle motivated the orchiectomy. In the pathological study, a hemorrhagic infarction was confirmed.

The right testicle was surgically explored using the scrotal approach. We found a low insertion of the epididymis in relation to the testicle, and orchiopexy was performed.

\section{COMMENTS}

Two types of spermatic cord torsion are described in literature. In the extravaginal torsion, the testicle and the vaginal sac turn over the spermatic cord at the external inguinal ring, due to a lack of adherence of the tunica vaginalis to the scrotal wall. This type of rotation can only be seen in fetus and neonates (2). In the intravaginal torsion, there is a previous anatomic defect. The high and narrow insertion of the tunica vaginalis in the testicle allows it to remain free in the vaginal sac as a "bell clapper". This kind of defect would be bilateral and would justify preventive orchiopexy in the contralateral testis (3). Another type of intravaginal torsion is between the testis and the epididymis. This rare presentation is reported only in disjunction between testis and epididymis (4). In this type of anatomic defect, isolated epididymis torsion has been reported. Also, torsion of the testicular and epididymal appendages can occur. These structures can turn over their own axis and produce pain and local inflammation, mimicking the clinical presentation of spermatic cord torsion (3).

In the present case, the unusual presentation with hardness and painless testicle in a young male patient, together with unspecific complementary

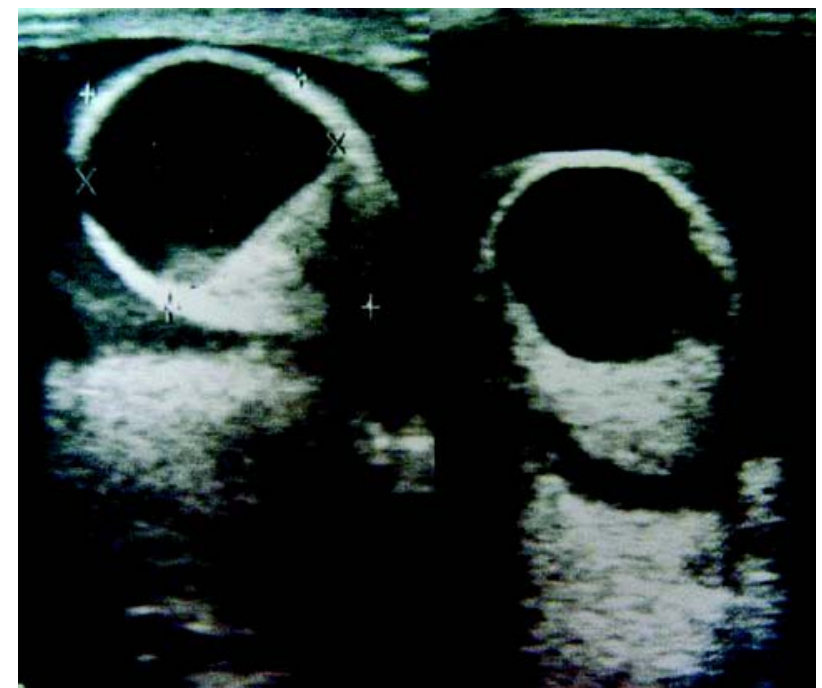

Figure 1 - Paratesticular solid hypoechoic mass.

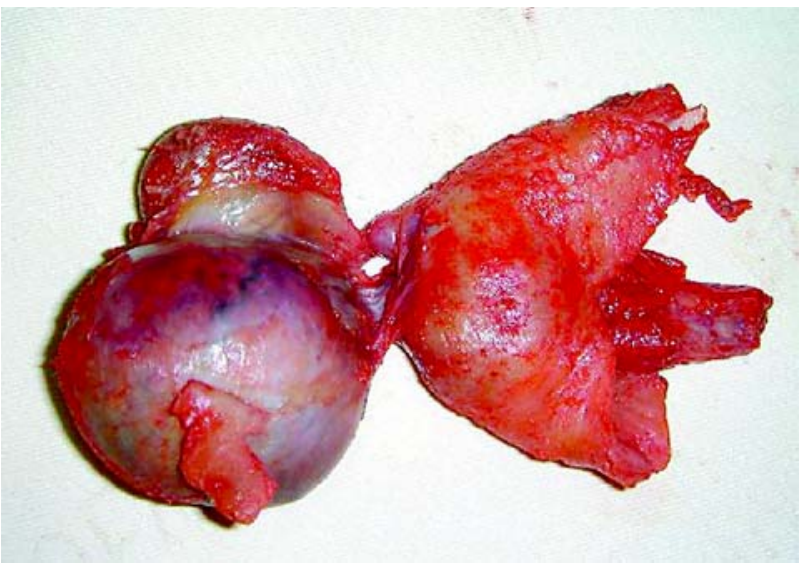

Figure 2 - Torsion in the epididymis corpus, leaving the head in place.

studies, lead us to think it was a testicular cancer and therefore, an inguinal approach was performed.

\section{CONFLICT OF INTEREST}

None declared.

\section{REFERENCES}

1. Scorer CG, Farrinfton GH: Congenital Deformities of the Testis and Epididymis. London, Butterworth and Co. 1971. 
2. Friedman RM, Flashner SC, Akwari OE, King LR: An experimental model of neonatal testicular torsion: evidence against an exclusively extravaginal etiology. J Urol. 1993; 150: 246-8.

3. Heinen F: Escroto Agudo. Arch Argent Pediatr. 2001; 99: 554-61.

\section{Correspondence address:}

Dr. Salomon Victor Romano

25 de mayo 846

Vicente Lopez, BA, 1638, Argentina

Fax: + 5411 4791-6735

E-mail: sromano1@arnet.com.ar

\section{EDITORIAL COMMENT}

The case-report herein describes an anecdotal situation of painless testicular torsion of the spermatic cord in an unusual location. The reader should bear in mind the rarity of this clinical event. On the other hand, the subject raised allows the editor to draw some reflections about this still controversial issue of acute scrotum. The main differential diagnosis of the acute scrotum includes testicular torsion and inflammatory conditions. Color Doppler ultrasound is the current imaging modality of choice for the radiological evaluation of acute scrotum, replacing other methods such as nuclear scintigraphy, Doppler flowmetry and gray scale ultrasound. Unfortunately, we cannot always rely on the exam. Bentley et al. discussed variations in degrees of bell clapper deformity and its influence in attachments of tunica vaginalis representing possibility of testicular blood flow despite spermatic cord torsion (1). In their series, 4 of 14 cases had testicular torsion confirmed intraoperatively despite a normal color Doppler ultrasound. One should also remember that ultrasound is an operator dependent test and a false-negative report may end catastrophically.

A more appealing and rational algorithm for the management of acute scrotum is also discussed in the paper of Bentley et al (1). In case of obvious suspicion of testicular
4. Ravichandran S, Blades RA, Watson ME: Torsion of the epididymis: a rare cause of acute scrotum. Int $\mathbf{J}$ Urol. 2003; 10: 556-7.

Accepted after revision: July 10, 2006

cord torsion, surgical operation is mandatory. When there is a low index of suspicion, one should perform color Doppler ultrasound and the diagnosis of inflammation is acceptable only in case of increased flow, while patients with "normal flow" should be also operated. We agree with others that 6 hours is the desirable time form the beginning of the onset of pain to have the case resolved.

\section{REFERENCE}

1. Bentley DF, Ricchiuti DJ, Nasrallah PF, McMahon DR: Spermatic cord torsion with preserved testis perfusion: initial anatomical observations. J Urol. 2004; 172: 2373-6.

Dr. Antonio Macedo Jr. Division of Urology Federal University of São Paulo, UNIFESP São Paulo, SP, Brazil E-mail: amcdjr@uol.com.br 